\title{
Radiosensitization of breast cancer cells by TRAIL-endostatin-targeting gene therapy
}

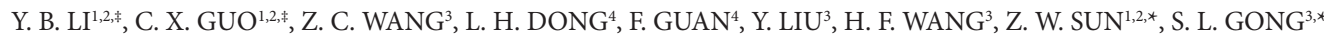 \\ ${ }^{1}$ School of Public Health, Capital Medical University, Beijing, 100069, P.R. China; ${ }^{2}$ Beijing Key Laboratory of Environmental Toxicology, Capital \\ Medical University, Beijing 100069, China; ${ }^{3}$ Key Laboratory of Radiobiology, Ministry of health, School of Public Health, Jilin University, Changchun, \\ 130021, Jilin Province, P.R. China; ${ }^{4}$ Nuclear Medicine, The First Hospital of Jilin University, Changchun, 130021, Jilin Province, P.R.China
}

*Correspondence: gongsl@163.com,zwsun@hotmail.com

${ }^{*}$ Contributed equally to this work.

Received November 14, 2012 / Accepted March 22, 2013

\begin{abstract}
One of the key issues in cancer radiotherapy research is to sensitize tumor cells to the cell killing effects of ionizing radiation while leaving normal tissues intact. One potential approach to achieve this is gene-radiotherapy, i.e. a combination of radiation therapy and gene therapy. It is to choose certain exogenous radiation-inducible regulatory genes, for example, early growth response-1 (Egr-1), and transcript its downstream tumor-therapeutic genes under ionizing radiation so as to kill the tumor cells synergistically by the expressed gene products together after transfection and irradiation exposure. In this study, we engineered a plasmid encoding both TRAIL and endostatin under the control of the radiation-inducible Egr-1 promoter, and evaluated its anti-tumor efficacy in combination with radiotherapy. Our plasmid showed significant efficacy in up-regulating the levels of TRAIL and endostatin proteins after transfected into breast cancer cells and exposed to X-ray irradiation. The detected cellular effects in vitro manifested that TRAIL-endostatin-based gene therapy could enhance radiosensitizing effects in breast cancer cells in terms of tumor cell growth inhibition, promoting apoptosis and the induction of cell cycle arrest. In summary, our results suggest that TRAIL-endostain-targeting approach might be a promising method to sensitize solid tumors to radiation therapy.
\end{abstract}

Key words: gene-radiotherapy, endostatin, TRAIL, Egr-1

Breast cancer is the most common and one of the most dangerous types of cancer in women all over the world, ranking the second leading cause of cancer deaths in them [1]. Radiation therapy is commonly used in the primary or adjuvant setting for treatment of various solid tumors. Currently, the delivery of radiation to the tumor can be achieved in a targeted manner, especially with new technologies such as Intensity Modulated Radiation Therapy (IMRT), which makes delivery of radiation therapy even more accurate. However, even with increased precision radiotherapy has its limits. One of the main disadvantages of radiation therapy is the damage to normal tissues that are irradiated during radiotherapy. Therefore, new agents that can selectively increase the radiation sensitivity of tumor cells are highly desired because they may enhance the efficacy of radiotherapy significantly without increasing damage to adjacent normal tissues.

Gene-radiotherapy, put forward by Weichselbaum et al. [2], may be a good option. On the one hand, it takes advantage of the dual tumor-killing effects of gene therapy and radiotherapy. Gene therapy may result in radiosensitization or additive cell killing effect, while the ionizing radiation improves transfection or transduction of therapeutic genes [3]. On the other hand, due to the targeting and controllability of ionizing radiation, it could regulate the gene expression in a temporal, spatial and dose-dependent way, which limits the radical damage to the surrounding normal tissues $[4,5]$. Nowadays, gene-radiotherapy has great potential and effective antitumor response for the treatment of local and distant diseases in vitro and in vivo $[6,7]$. In considering of tumor belonging to a polygene disease, it might be an ideal option to apply two or more therapeutic genes therapy combined with radiotherapy for tumor treatment.

Apoptosis is closely associated with the development of tumors. Tumor necrosis factor-related apoptosis inducing ligand (TRAIL), also known as Apo2 ligand, Apo2L, was identified as a member of the tumor necrosis factor (TNF) superfamily [8, 
9]. Unlike other TNF family member, TRAIL can specifically induce apoptosis in a broad range of tumor cells, but not in most normal cells and tissues [10]. With respect to its tumor specificity, TRAIL was considered as a potential therapeutic agent for tumor therapy $[11,12]$.

Antiangiogenic approaches, suppressing the tumor vasculatures, have emerged as an attractive strategy for cancer treatment. Until now, a large number of angiogenic inhibitors are identified, such as endostatin (ES), platelet factor 4 , angiostatin and vasostatin. Among these, endostatin, an endogenous angiogenesis inhibitor [13], has been reported to have significant antitumor effects in a variety of tumor models, including inhibiting proliferation and inducing apoptosis of the endothelial cells in vitro, and suppressing tumor growth and metastases in nude mice with no signs of toxicity or acquired drug resistance. Recently, for TRAIL or endostatin therapy, most studies utilize its purified recombinant protein. However, in order to obtain prolonged anti-tumor effect, the recombinant protein needs frequent, long-term administration and high doses for desired effect due to the short half-time [14] and instability of systemically delivery [15]. However, gene therapy may overcome this problem.

The expression of early growth response-1 (Egr-1) gene is transcriptionally induced by irradiation, which attributes to the six CArG elements in its promoter region [16]. Using Egr-1 as the promoter, the expression of downstream genes, TRAIL and endostatin, can be greatly enhanced by X-rays. In the present study, we evaluated the efficacy of TRAIL-endostatin-targeting gene therapy to sensitize human breast cancer to radiation therapy. A radiation-inducible double gene co-expressing plasmid, pshuttle-Egr1-shTRAIL-shES could efficiently secretory express TRAIL and endostatin proteins under the exposure to $\mathrm{X}$-rays, and demonstrated enhanced sensitization to ionizing radiation on breast cancer cells in vitro.

\section{Materials and methods}

Plasmids. Pshuttle was presented by Dr. Lisheng Wang from Institute of Radiation Medicine and Radiation Protection, Academy of Military Medical Sciences. Recombinant plasmids, pshuttle-Egr1-shTRAIL [17], pshuttle-Egr1-shES and pshuttle-Egr1-shTRAIL-shES [18], were constructed by our laboratory. Among the plasmid names, "sh" is short for secretory human, representing that the human TRAIL or endostatin could secrete expression based on a secretory signal peptide directly linked on the corresponding cDNA.

Cell culture and treatment. The human breast cancer cell line, MCF-7, was purchased from Shanghai Cell Bank, Chinese Academy of Sciences. The cells were cultured in DMEM medium (Gibco, USA) supplemented with 10\% FBS (Gibco, USA) in a humidified incubator with $5 \% \mathrm{CO}_{2}$ at $37^{\circ} \mathrm{C}$, and subcultured by trypsinizaiton with $0.25 \%$ trypsin when they reached $80 \%$ - 90\% confluence. First, cells were treated with plasmid transfection and grouped according to the name of tranfected plasmids. Also set the non-transfected cells as control. Later, cells in each group were exposed to $\mathrm{X}$-ray irradiation.

$\mathrm{X}$-ray irradiation. X-ray irradiation was carried out by a Phillips deep X-ray apparatus with the setting of $200 \mathrm{kV}, 10$ $\mathrm{mA}$ and filters of $0.5 \mathrm{~mm} \mathrm{Cu}$ and $1.0 \mathrm{~mm} \mathrm{Al}$ to deliver doses of $0.1-0.75 \mathrm{~Gy}$ at a dose-rate of $12.5 \mathrm{mGy} / \mathrm{min}$ and a target skin distance of $243.7 \mathrm{~cm}$, and $1-5 \mathrm{~Gy}$ at a dose-rate of 0.287 $\mathrm{Gy} / \mathrm{min}$ and a target skin distance of $50 \mathrm{~cm}$.

Cell transfection. The cells were transfected by plasmids with the lipofectamine ${ }^{\mathrm{TM}} 2000$ reagent (invitrogen, USA) according to the manufacturer's instructions. The cells were incubated at $37^{\circ} \mathrm{C}$ for $6 \mathrm{~h}$, and then the transfection media were replaced by fresh complete growth media.

ELISA. Transfected MCF-7 cells were exposed to 0, 0.1, 0.5, 1.0, 2.0 and 5.0 Gy irradiation, and culture supernatants were collected at different time points for TRAIL and endostatin determination. TRAIL and endostatin concentrations in the culture supernatants were determined by enzyme-linked immunosorbent assay (ELISA, R\&D, Minneapolis, USA) according to the manufacturer's instructions.

Cell viability. The effect of TRAIL-endostatin-targeting gene-radiotherapy on cell viability in MCF-7 cells was assessed by MTT assay. After seeded in 96-well plates at density of $6 \times 10^{4}$ cells/well and incubated overnight, the cells were transfected with pshuttle, pshuttle-Egr1-shTRAIL, pshuttleEgr1-shES and pshuttle-Egr1-shTRAIL-shES respectively for $24 \mathrm{~h}$ as described above. Then the plates were divided into two groups, one for studying the dose-response effect and the other for time-course effect. The former were exposed to Xray irradiation at various doses $(0,0.1,0.5,1.0,2.0$ and $5.0 \mathrm{~Gy}$ respectively). After incubation for $24 \mathrm{~h}, 20 \mu \mathrm{lof} 5 \mathrm{mg} / \mathrm{ml}$ MTT (Sigma, USA) were added into each well for additional 4-hour incubation to form formazan crystals. Afterwards, medium was discarded, and $150 \mu \mathrm{l}$ of DMSO was added into each well and incubated for 10-15 min in order to dissolve formazan crystal. Ultimately, the absorbance value at $490 \mathrm{~nm}, A_{490}$ was determined by microplate reader (Therm, USA). Meanwhile, the plates for time-course effect were irradiated by X-ray at a dose of $2.0 \mathrm{~Gy}$ after transfection for $24 \mathrm{~h}$. At the different time-point $(2,4,8,12,24,36$ and $48 \mathrm{~h}$ respectively), the cells were detected by MTT assay as described above.

Cell cycle progression. Cell cycle progression was detected by FCM with PI staining. After transfection with plasmids for $24 \mathrm{~h}$ as described above, the cells were exposed to $2.0 \mathrm{~Gy} \mathrm{X}$ ray. Twelve hours later, the cells were harvested and washed twice with PBS. Then $0.3 \%$ Triton X-100, $150 \mu \mathrm{l}$ PI $(5 \mu \mathrm{g} / \mathrm{ml})$ and $50 \mu \mathrm{l} \mathrm{RNase}(10 \mu \mathrm{g} / \mathrm{ml})$ were added into each sample and incubated at $4^{\circ} \mathrm{C}$ in the dark for $30 \mathrm{~min}$. The samples were detected by flow cytometer (Becton Dickinson, USA), and analyzed with a minimum of 10,000 cells within the grated region using the Modifit software.

Apoptosis. The quantification of apoptosis induced by TRAIL-endostatin-targeting gene-radiotherapy in MCF-7 cells was measured by FCM with Annexin V-FITC/PI double 
staining assay. Briefly, after done with the plasmid transfection for $24 \mathrm{~h}$, the cells were exposed to $2.0 \mathrm{~Gy}$ X-ray. 24 hours later, the cells were harvested and then stained by using Annexin V-FITC/PI apoptosis assay kit (KeyGen, Nanjing, China) according to the kit instructions. At least 10,000 cells were collected and detected by flow cytometer (Becton Dickinson, USA) within $15 \mathrm{~min}$. The apoptotic percentages were determined by FACADiva 4.1 software.

Statistical analysis. The data sets analyzed were well modeled by a normal distribution. Hence the data were presented as mean \pm standard deviation (SD), and analyzed by SPSS 14.0 software. One-way ANOVA with least significant difference (LSD) test was used to assess the differences between groups. Differences were considered significant at $p<0.05$.
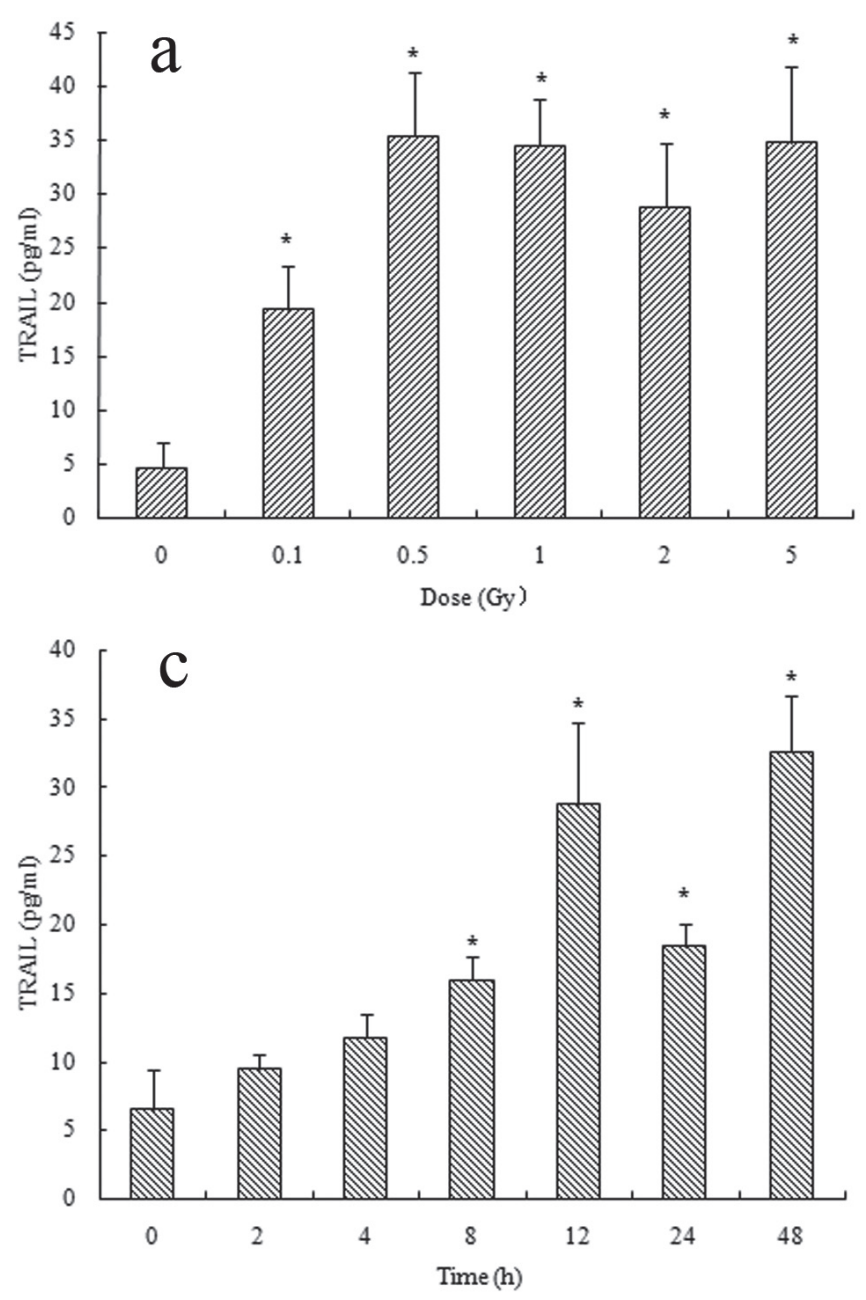

\section{Results}

Effectively enhanced expression of TRAIL and endostatin by $\mathrm{X}$-ray irradiation. Firstly, the recombinant plasmid pshuttle-Egr1-shTRAIL-shES was transferred into MCF-7 cells in vitro. Then the secretory expressions of TRAIL and endostatin induced by X-ray were determined by ELISA. As shown in Figure 1a and $\mathrm{b}$, under the exposure of X-ray irradiation of different doses, a dose-dependent increase of TRAIL and endostatin release was manifested in the supernantant of plasmid transfected MCF- 7 cells $(P<0.01$ versus 0 Gy). Meanwhile, as the prolongation of the post-irradiation time, the expressions of TRAIL and endostatin on the plasmid transfected MCF-7 cells were also enhanced significantly $(P<0.01$ versus $0 \mathrm{~h}$; Figure $1 \mathrm{c}$ and $\mathrm{d}$ ).
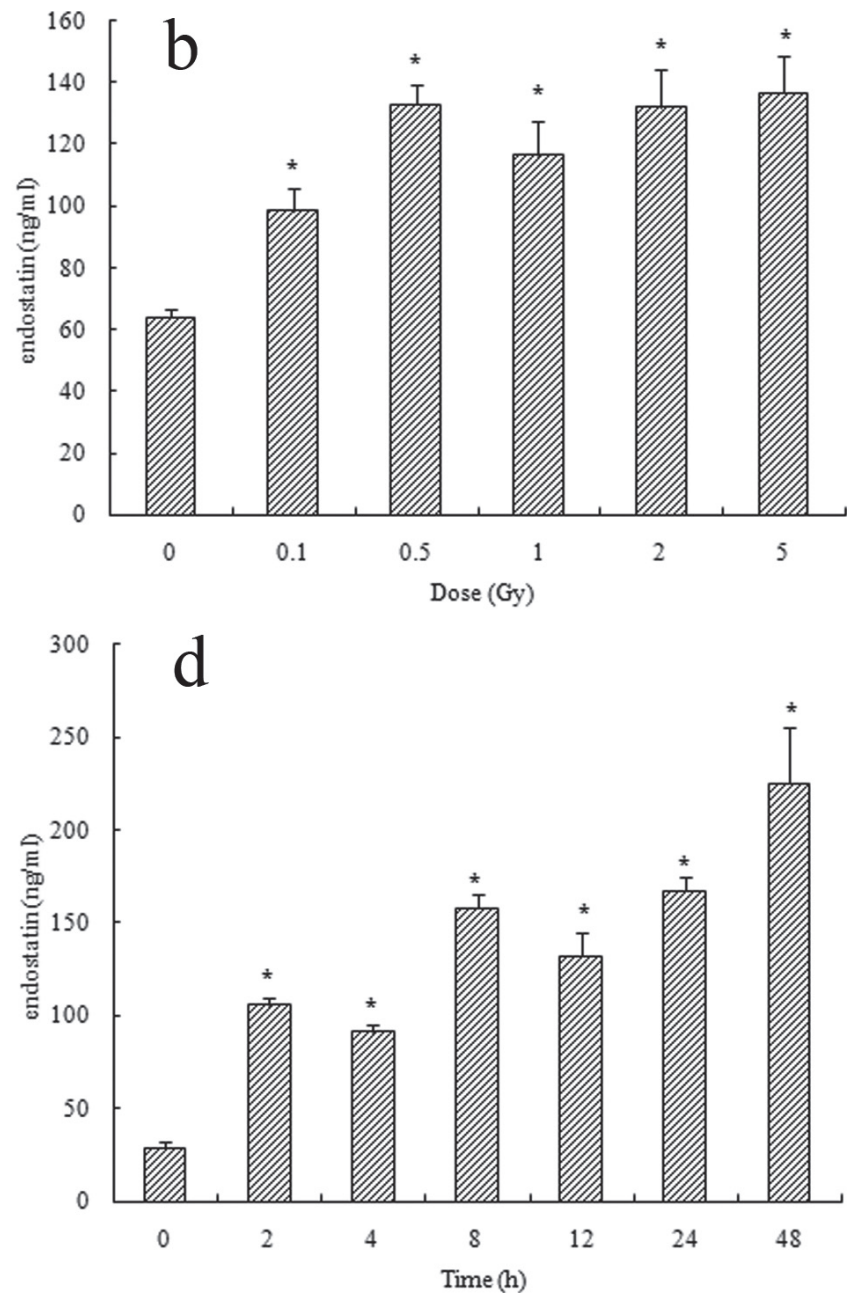

Figure 1. Dose- and time-dependent release of TRAIL and endostatin from pshuttle-Egr1-shTRAIL-shES transfected MCF-7 cells after irradiation. Human breast cancer cell line, MCF-7 cells were transfected with pshuttle-Egr1-shTRAIL-shES for $24 \mathrm{~h}$, and then exposed to X-ray irradiation at 0.1-5.0 Gy for $12 \mathrm{~h}(\mathrm{a}, \mathrm{b})$ or at $2.0 \mathrm{~Gy}$ for 2-48 h (c, d). The concentrations of TRAIL and endostatin protein expressions in the culture supernatants were assessed by ELISA. Values were showed as mean \pm SD from three independent experiments. ${ }^{*} P<0.01 v s$ control 
a

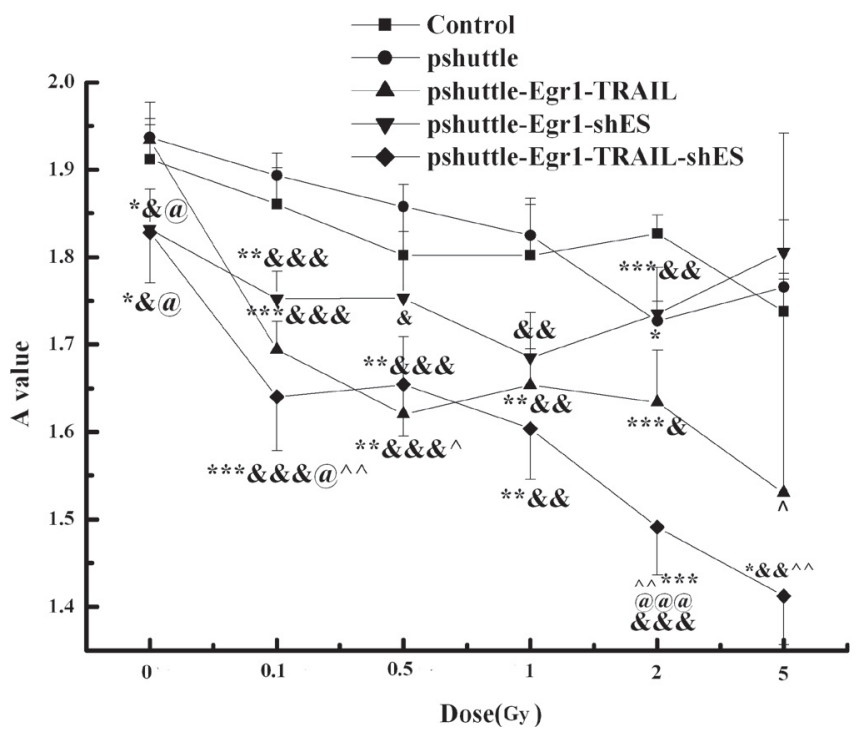

b

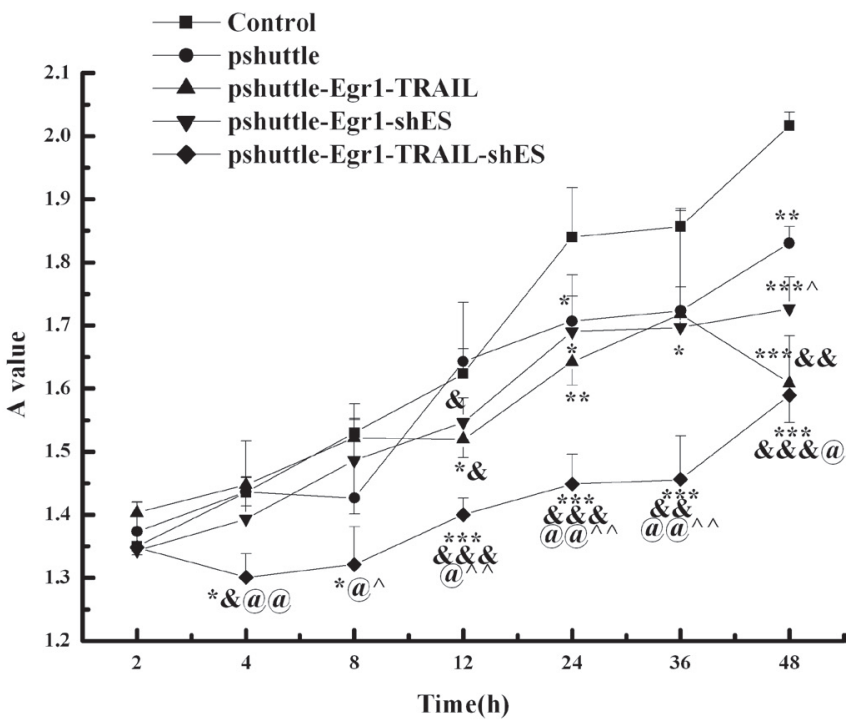

Figure 2. TRAIL-endostatin-targeting gene therapy combined with irradiation results in growth inhibition of tumor cells in vitro. The MCF-7 cells were transfected with plasmid pshuttle, pshuttle-Egr1-shTRAIL, pshuttle-Egr1-shES and pshuttle-Egr1-shTRAIL-shES respectively for 24 h, and then exposed to X-ray irradiation at at 0.1-5.0 Gy for 24 h (a) or at 2.0 Gy for 2-48 $\mathrm{h}$ (b) as described in the "Materials and Methods" section. The cell viability was determined by MTT assay. The $A_{490}$ values reported were showed as mean \pm SD from three independent experiments. ${ }^{*} P<0.05$, ${ }^{* *} P<0.01$ and ${ }^{* * *} P$ $<0.001$ vs control; ${ }^{\&} P<0.05,{ }^{\& \&} P<0.01$ and ${ }^{\& \& \&} P<0.001$ vs pshuttle; ${ }^{\circledR} P<0.05$, ${ }^{@} P<0.01$ and ${ }^{@ @ @ ~} P<0.001$ vs pshuttle-Egr1-shTRAIL; ${ }^{\wedge} P<0.05$ and $\wedge \wedge P<0.01 v s$ pshuttle-Egr1-shES

TRAIL-endostain-targeting gene therapy in enhancing the tumor growth inhibition induced by radiation therapy. To evaluate whether the enhanced expression of TRAIL-endostatin is sufficient to sensitize breast cancer cells to the cell-killing effect of ionizing radiation, MCF-7 cells were transfected with plasmids containing TRAIL and/or endostatin gene, and then the cell viability before and after $\mathrm{X}$-ray irradiation at various dose was evaluated with the MTT assay. As shown in Figure 2a, the cell viability was declined after irradiation along with the enlargement of the irradiation dose. Furthermore, it was clear to observe that the pretreatment of TRAIL and/or endostatin transfection in MCF-7 before irradiation had little effect on cell viability, while manifested significant decrease on the cell viability of MCF-7 cells after irradiation, and exhibited a dose-dependent manner. In addition, the time-effect results showed that the TRAIL and/or endostatin pre-treatment induced a retardation of the timedependent increase of cell viability after radiation in MCF-7 cells, especially the simultaneous expression of TRAIL and endostatin (Figure 2b). In summary, MTT results indicated that TRAIL-endostatin-based gene-therapy could enhance the tumor cell growth inhibition effect induced by radiation, especially the double gene treatment.

TRAIL-endostain-targeting gene therapy in enhancing the blockade in cell cycle progression mediated by radiation therapy. Presently, it is generally believed that cell phase is crucial for determining cell radiosensitivity. To investigate whether TRAIL-endostatin-targeting gene-radiotherapy affects cell cycle progression, FCM with PI staining was used to quantify changes in the cell cycle. As shown in Figure 3, the pre-treatment of TRAIL and/or endostatin gene combined with radiation induce a significant decline of the percentage of $\mathrm{G}_{0} / \mathrm{G}_{1}$ phase cells, and a remarkable increase of that of $S$ phase cells as compared with the radiation alone.

TRAIL-endostain-targeting gene therapy in enhancing the apoptosis promotion mediated by radiation therapy. To analyze whether TRAIL-endostatin-targeting gene therapy affects radiation induced cell apoptosis, we quantified the proportion of apoptotic cells after X-ray irradiation alone and the combined modality of gene-radiotherapy. As shown in Figure 4 , it was clearly observed that ionizing radiation induced slight apoptosis in MCF-7 cells. It is noted that in combination with 2.0 Gy X-irradiation, pre-treatment of TRAIL and/or endostatin gene induced marked apoptosis in MCF-7 cells, especially the simultaneously dual-gene treatment with the maximal apoptotic percentage.

\section{Discussion}

The radiation damage to normal tissues surrounding and radiation resistance of some tumors limits the efficacy and application of radiotherapy. Gene therapy brings hope for tumor therapy research. The leukemia or leukemia like disease co-occurring in gene therapy made the safety and target of 
gene therapy in clinical application draw much attention [19, 20]. Nowadays, in tumor gene therapy research, it would be highly preferable if the therapeutic genes were just expressed in the local targeted tumor tissues by taking advantage of the tumor-specific promoter, radiation-inducible promoter or hypoxia promoter, etc. Egr-1 promoter has the function of radiation-inducible enhanced expression of anti-tumor genes [21]. Weichselbaum et al. [22] firstly constructed the recombinant plasmid pEgr-TNF, and their research showed that as compared with that in the control group, the TNF- $\alpha$ expression in local SQ-20B (human squamous cell carcinoma cell line) xenograft tumor tissue increased to 2.7 times after $\mathrm{X}$-ray irradiation when injecting the hematopoietic stem cell HL-525 transfected with pEgr-TNF into tumor, and tumor growth was significantly inhibited without the increase of local and systemic toxicity. Since then, Egr-1 promoter was widely applied into tumor gene-radiotherapy.

It is critical to select effective therapeutic genes and establish an effective gene delivery system in gene-radiotherapy. In general, virus vectors are generally more toxic, immunogenic and pathogenic as compared with non-viral vectors despites having been preferentially applied for gene therapy. On the contrary, the non-viral vectors are simpler and relatively safer. Since tumor is a multiple-gene disease, some researchers started to focus on double or multiple gene-radiotherapy. Yang and Li [23] showed that the antitumor effect of interferon gamma (IFN $\gamma$ )-endostatin-based double-gene-radiotherapy was better than single-gene-radiotherapy, and gene therapy or radiation alone. The triple combination of IL-2 gene, IL-12 gene and radiation was demonstrated to have preferable antitumor effect as compared with single or randomly combined therapy of two in three [24]. Therefore, in the present study, we engineered a plasmid encoding both TRAIL and endostatin under the control of the radiation-inducible Egr-1 promoter, and then evaluated its anti-tumor efficacy in combination with radiotherapy.

Results confirmed that our plasmid had significant efficacy in up-regulating the levels of TRAIL and endostatin proteins after transfected into breast cancer cells and exposed to X-ray irradiation. In the plasmid construction, an internal ribosome entry site (IRES) was incorporated into the vector with the aim of simultaneous expression of several gene products under the transcriptional control of the same promoter. The IRES element permits the translation of two open reading frames from one messenger RNA. Taking advantage of DNA recombinant technique, a radiation-inducible dual-gene co-expression vector pshuttle-Egr1-shTRAIL-shES was constructed, in which TRAIL and endostatin genes were positioned upstream and downstream of the IRES element respectively. The plasmid was transferred into breast cancer cells by lipofectamine-mediated method, and the dose-effect, time-course rules of TRAIL and endostatin expressions induced by X-ray were investigated. Results showed that our plasmid had significant efficacy in up-regulating the levels of TRAIL and endostatin proteins after transfected into breast cancer cells and exposed to X-ray

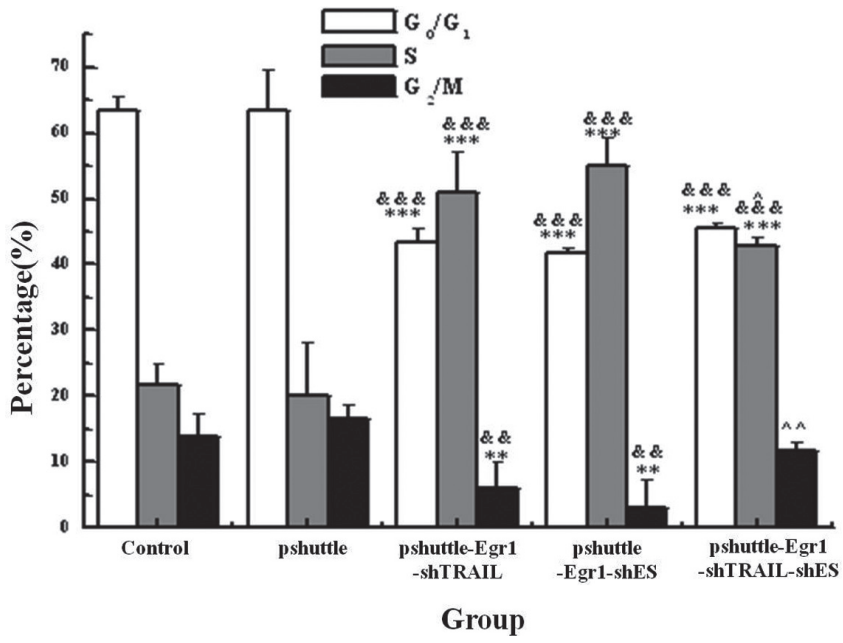

Figure 3. TRAIL-endostatin-targeting gene therapy combined with irradiation results in cell cycle arrest. Briefly, cells were transfected with recombinant plasmids, and irradiated by $2.0 \mathrm{~Gy} \mathrm{X}$-ray as mentioned in Fig. 2. Twelve hours later, cells were collected and measured by FCM with PI staining as described in the "Materials and Methods" section. The values standing for the percentages of each phase cells were analyzed by Modifit software, and showed as mean \pm SD from three independent experiments. ${ }^{* *} P<0.01$ and ${ }^{* * *} P<0.001 v s$ control; ${ }^{* *} P<0.01$ and ${ }^{* * *} P$ $<0.001$ vs pshuttle; $\wedge P<0.05$ and $\wedge \wedge P<0.001$ vs pshuttle-Egr1-shES

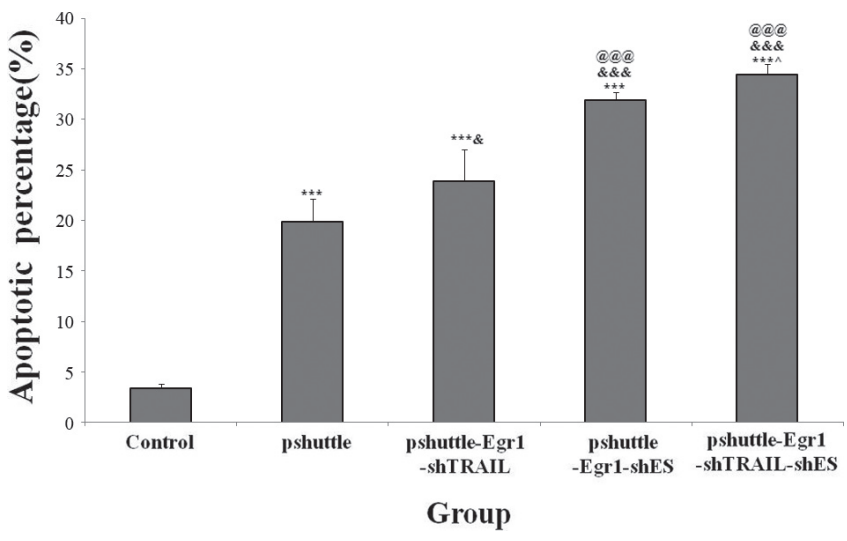

Figure 4. TRAIL-endostatin-targeting gene therapy combined with irradiation results in increased apoptosis in MCF-7 cells. Briefly, the MCF-7 cells were transfected with recombinant plasmids, namely pshuttle, pshuttle-Egr1-shTRAIL, pshuttle-Egr1-shES and pshuttle-Egr1shTRAIL-shES respectively for $24 \mathrm{~h}$, and then exposed to $2.0 \mathrm{~Gy} \mathrm{X}$-irradiation. Twenty-four hours later, cells were collected and measured by FCM with Annexin V and PI double staining as described in the "Materials and Methods" section. The values of apoptotic rate analyzed by FCM were showed as mean \pm SD from three independent experiments. ${ }^{* * *} P<$ 0.001 vs control; ${ }^{\circledR} P<0.05$ and ${ }^{\& \& \&} P<0.001$ vs pshuttle; ${ }^{\circledR @ @ ~} P<0.001$ vs pshuttle-Egr1-shTRAIL; $\wedge P<0.05$ vs pshuttle-Egr1-shES

irradiation. However, it was reported that IRES-dependent second gene expression is significantly lower than the first gene expression in this vector system [25]. Our results were 
coincident with this phenomenon. After 5.0 Gy X-ray irradiation, the expressions of TRAIL and endostatin reached the highest, which were 7.56 and 2.14 times as much as that in 0 Gy group respectively.

It was reported that TRAIL could induce apoptosis in tumorigenic or transformed cells, and its mechanisms are mediated mainly by the binding of TRAIL and death receptor DR4 or DR5, further inducing the formation of death-inducing signaling complex (DISC), activating caspase-8, and then initiating the mitochondrial dependent or independent apoptotic pathway [26,27]. Endostatin could inhibit the cell proliferation and migration, cause cell cycle arrest, and induce apoptosis of vascular endothelial cells, reduce tumor vascularization and slow down the tumor growth $[28,29]$. Endostatin was also demonstrated to have the effects of strong anti-proliferation, causing cell cycle arrest and promoting apoptosis on human ovarian cancer cell line SKOV3 and human colon adenocarcinoma cell line HT29 and C51 [30].

During tumorigenesis, tumor cells tend to unlimited growth and frequently loose checkpoint controls, which facilitate the development of the tumor. Cell cycle regulation is perhaps the most important determinant of ionizing radiation sensitivity. There is no doubt that DNA is the critical target in radiation. Irradiation induces both single- and double-strand DNA breaks, with the double-strand breaks generally considered the lethal event. The DNA damage induced by ionizing radiation initiates signals that can ultimately activate either temporary checkpoints that permit time for genetic repair or irreversible growth arrest that results in cell death (necrosis or apoptosis). Therefore, to evaluate whether TRAIL-endostatinbased gene therapy could be a radiosensitizer, the effects on tumor cell growth, cell cycle progression and apoptosis were determined.

The detected cellular effects in vitro manifested that TRAILendostatin-based gene therapy could enhance radiosensitizing effects in breast cancer cells in terms of tumor cell growth inhibition, promoting apoptosis and the induction of cell cycle arrest in S phase, especially the dual-gene-radiotherapy with the best anti-tumor efficacy. Although we did not detect DNA damage in our experiment, cell cycle arrest could reflect the degree of DNA damage in some extent. As we know, DNA replication occurs during $S$ phase. The cell cycle delay in $S$ phase could offer more time for the repair of damaged DNA and protect cells from the genomic instability. Once the DNA injuries exceed the intrinsic repair capacity of cells, apoptosis or cell death would occur thereafter. In addition, seen from the dose-effect data acquired by MTT, the dual-gene plus 2.0 Gy irradiation resulted in lower in $A_{490}$ value than either the 5.0 Gy irradiation alone or in combination with single gene therapy, while the dual-gene plus $1.0 \mathrm{~Gy}$ irradiation induced lower in $A_{490}$ value than 2.0 Gy irradiation alone or in combination with single gene, and also the dual-gene plus $0.5 \mathrm{~Gy}$ irradiation had lower $A_{490}$ value than the 1.0 Gy radiation alone or in combination with single gene. The phenomenon revealed that the use of TRAIL-endostatin dual-gene therapy as a radiosensitizer in combination with irradiation is beneficial to increase the therapeutic efficacy and lower radiation dose to protect the neighboring normal tissue.

In summary, TRAIL-endostain-targeting approach might be a promising method to sensitize solid tumors to radiation therapy. The three combined modality could increase the anti-tumor efficacy and provides a synergistic therapeutic effect by combining the direct killing effect of radiation, TRAIL-induced apoptosis specifically in tumor cells and endostatin-associated antitumor effects, including antiangiogensis, promoting apoptosis and causing cell cycle arrest, etc. The synergistic effect between TRAIL and ionizing radiation might be associated with the radiation-induced selective upregulation of the surface expression of TRAILreceptors, DR5 and TRAIL-R1 (DR4) [31, 32]. However, as for the related mechanisms of the synergistic effect of the combination of TRAIL, endostatin and radiation, it needs to be elucidated. While we do believe TRAIL-endostatin-targeting approach combined with irradiation as a good pointcut, may result in better anti-tumor effect, and represents a useful addition to neoadjuvant management of locally advanced breast cancer.

Acknowledgements: This work was supported by the grants from the National Natural Science Foundation of China (No.30570546).

\section{References}

[1] JEMAL A, SIEGEL R, WARD E, HAO Y, XU J, et al. Cancer statistics, 2009. CA Cancer J Clin 2009; 59: 225-49. http: //dx.doi.org/10.3322/caac.20006

[2] WEICHSELBAUM RR, HALLAHAN DE, SUKHATME VP, KUFE DW. Gene therapy targeted by ionizing radiation. Int J Radiat Oncol Biol Phys 1992; 24: 565-7. http: //dx.doi. org/10.1016/0360-3016(92)91075-X

[3] KALIBEROV SA, KALIBEROVA LN, BUCHSBAUM DJ. Combined ionizing radiation and sKDR gene delivery for treatment of prostate carcinomas. Gene Ther 2005; 12: 407-17. http: //dx.doi.org/10.1038/sj.gt.3302432

[4] KHODAREV NN, PARK JO, YU J, GUPTA N, NODZENSKI E, et al. Dose-dependent and independent temporal patterns of gene responses to ionizing radiation in normal and tumor cells and tumor xenografts. Proc Natl Acad Sci U S A 2001; 98: 12665-70. http: //dx.doi.org/10.1073/ pnas. 211443698

[5] MIN FL, ZHANG H, LI WJ. Current status of tumor radiogenic therapy. World J Gastroenterol 2005; 11: 3014-9.

[6] YANG J, JIN G, LIU X, LIU S. Therapeutic effect of pEgrIL18-B7.2 gene radiotherapy in B16 melanoma-bearing mice. Hum Gene Ther 2007; 18: 323-32. http://dx.doi.org/10.1089/ hum.2006.133

[7] JIN GH, JIN SZ, LIU Y, XU RM, YANG JZ, et al. Therapeutic effect of gene-therapy in combination with local $\mathrm{X}$-irradiation in a mouse malignant melanoma model. Biochem Biophys Res Commun 2005; 330: 975-81. http: //dx.doi.org/10.1016/ j.bbrc.2005.03.070 
[8] WILEY SR, SCHOOLEY K, SMOLAK PJ, DIN WS, HUANG CP, et al. Identification and characterization of a new member of the TNF family that induces apoptosis. Immunity 1995; 3: 673-82. http: //dx.doi.org/10.1016/1074$\underline{7613(95) 90057-8}$

[9] PITTI RM, MARSTERS SA, RUPPERT S, DONAHUE CJ, MOORE A, et al. Induction of apoptosis by Apo-2 ligand, a new member of the tumor necrosis factor cytokine family. J Biol Chem 1996; 271: 12687-90. http://dx.doi.org/10.1074/ jbc.271.22.12687

[10] ASHKENAZI A, HOLLAND P, ECKHARDT SG. Ligandbased targeting of apoptosis in cancer: the potential of recombinant human apoptosis ligand 2/Tumor necrosis factor-related apoptosis-inducing ligand (rhApo2L/TRAIL). J Clin Oncol 2008; 26: 3621-30. http: //dx.doi.org/10.1200/ LCO.2007.15.7198

[11] DUIKER EW, MOM CH, DE JONG S, WILLEMSE PH, GIETEMA JA, et al. The clinical trail of TRAIL. Eur J Cancer 2006; 42: 2233-40. http: //dx.doi.org/10.1016/j.ejca.2006.03.018

[12] YOO J, PARK SS, LEE YJ. Pretreatment of docetaxel enhances TRAIL-mediated apoptosis in prostate cancer cells. J Cell Biochem 2008; 104: 1636-46. http: //dx.doi.org/10.1002/ jcb.21729

[13] O'REILLY MS, BOEHM T, SHING Y, FUKAI N, VASIOS G, et al. Endostatin: an endogenous inhibitor of angiogenesis and tumor growth. Cell 1997; 88: 277-85. http: //dx.doi. org/10.1016/S0092-8674(00)81848-6

[14] KISKER O, BECKER CM, PROX D, FANNON M, D'AMATO $\mathrm{R}$, et al. Continuous administration of endostatin by intraperitoneally implanted osmotic pump improves the efficacy and potency of therapy in a mouse xenograft tumor model. Cancer Res 2001; 61: 7669-74.

[15] LEE J, HAMPL M, ALBERT P, FINE HA. Antitumor activity and prolonged expression from a TRAIL-expressing adenoviral vector. Neoplasia 2002; 4: 312-23. http: //dx.doi. org/10.1038/sj.neo.7900245

[16] WEICHSELBAUM RR, KUFE DW, ADVANI SJ, ROIZMAN B. Molecular targeting of gene therapy and radiotherapy. Acta Oncol 2001; 40: 735-8. http: //dx.doi. org/10.1080/02841860152619151

[17] LI YB, LIANG S, DONG LH, YANG W, GUO CX, et al. Construction and identification of recombinant adenoviral shuttle vector with radiation-inducible TRAIL gene (in Chinese). Journal of Jilin University (Medicine Edition) 2008; 34 : 364-368.

[18] LI YB, GUO CX, GONG PS, LIU Y, LIANG S, et al. Construction and identification of double-gene co-expression vector with radiation-inducible human TRAIL and endostatin (in Chinese). Journal of Jilin University (Medicine Edition) 2010; 36: 1007-11.

[19] LI Z, DULLMANN J, SCHIEDLMEIER B, SCHMIDT M, VON KALLE C, et al. Murine leukemia induced by retroviral gene marking. Science 2002; 296: 497. http: //dx.doi. org/10.1126/science. 1068893
[20] MARSHALL E. Clinical research. Gene therapy a suspect in leukemia-like disease. Science 2002; 298: 34-5. http: //dx.doi. org/10.1126/science.298.5591.34

[21] TSURUSHIMA H, YUAN X, DILLEHAY LE, LEONG KW. Radiation-inducible caspase- 8 gene therapy for malignant brain tumors. Int J Radiat Oncol Biol Phys 2008; 71: 517-25. http: //dx.doi.org/10.1016/j.ijrobp.2008.02.002

[22] WEICHSELBAUM RR, HALLAHAN DE, BECKETT MA, MAUCERI HJ, LEE $\mathrm{H}$, et al. Gene therapy targeted by radiation preferentially radiosensitizes tumor cells. Cancer Res 1994; 54: 4266-9.

[23] YANG W, LIXY. Anti-tumor effect of pEgr-interferon-gammaendostatin gene-radiotherapy in mice bearing Lewis lung carcinoma and its mechanism. Chin Med J (Engl) 2005; 118: 296-301.

[24] XIAN J, YANG H, LIN Y, LIU S. Combination nonviral murine interleukin 2 and interleukin 12 gene therapy and radiotherapy for head and neck squamous cell carcinoma. Arch Otolaryngol Head Neck Surg 2005; 131: 1079-85. http: //dx.doi.org/10.1001/archotol.131.12.1079

[25] MIZUGUCHI H, XU Z, ISHII-WATABE A, UCHIDA E, HAYAKAWA T. IRES-dependent second gene expression is significantly lower than cap-dependent first gene expression in a bicistronic vector. Mol Ther 2000; 1: 376-82. http: //dx.doi. org/10.1006/mthe.2000.0050

[26] Suliman A, Lam A, Datta R, SRIVASTAVA RK. Intracellular mechanisms of TRAIL: apoptosis through mitochondrialdependent and -independent pathways. Oncogene 2001; 20: 2122-33. http: //dx.doi.org/10.1038/sj.onc. 1204282

[27] GRIFFITH TS, ANDERSON RD, DAVIDSON BL, WILLIAMS RD, RATLIFF TL. Adenoviral-mediated transfer of the TNFrelated apoptosis-inducing ligand/Apo-2 ligand gene induces tumor cell apoptosis. J Immunol 2000; 165: 2886-94.

[28] FOLKMAN J. Antiangiogenesis in cancer therapy--endostatin and its mechanisms of action. Exp Cell Res 2006; 312: 594-607. http: //dx.doi.org/10.1016/j.yexcr.2005.11.015

[29] NYBERG P, XIE L, KALLURI R. Endogenous inhibitors of angiogenesis. Cancer Res 2005; 65: 3967-79. http: //dx.doi. org/10.1158/0008-5472.CAN-04-2427

[30] JIANG J, CHEN W, ZHUANG R, SONG T, LI P. The effect of endostatin mediated by human mesenchymal stem cells on ovarian cancer cells in vitro. J Cancer Res Clin Oncol 2010; 136: 873-81. http: //dx.doi.org/10.1007/s00432-009-0728-8

[31] CHINNAIYAN AM, PRASAD U, SHANKAR S, HAMSTRA DA, SHANAIAH M, et al. Combined effect of tumor necrosis factor-related apoptosis-inducing ligand and ionizing radiation in breast cancer therapy. Proc Natl Acad Sci U S A 2000; 97: 1754-9. http: //dx.doi.org/10.1073/pnas.030545097

[32] DI PIETRO R, SECCHIERO P, RANA R, GIBELLINI D, VISA$\mathrm{NI}$ G, et al. Ionizing radiation sensitizes erythroleukemic cells but not normal erythroblasts to tumor necrosis factor-related apoptosis-inducing ligand (TRAIL)--mediated cytotoxicity by selective up-regulation of TRAIL-R1. Blood 2001; 97: 2596-603. http: //dx.doi.org/10.1182/blood.V97.9.2596 